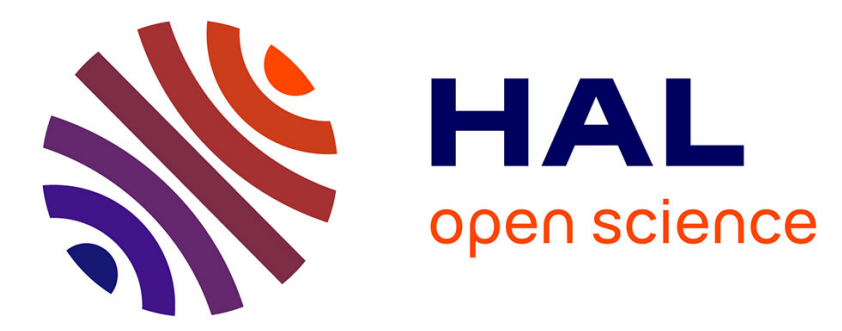

\title{
A new testing method to investigate the compacting behavior of fresh concretes under impact loading
}

\author{
Stéphane Pattofatto, Arnaud Poitou, H. Tsitisiris, Han Zhao
}

\section{To cite this version:}

Stéphane Pattofatto, Arnaud Poitou, H. Tsitisiris, Han Zhao. A new testing method to investigate the compacting behavior of fresh concretes under impact loading. Experimental Mechanics, 2006, 46 (3), pp.377-386. 10.1007/s11340-006-6419-3 . hal-01004916

\section{HAL Id: hal-01004916 https://hal.science/hal-01004916}

Submitted on 6 Feb 2017

HAL is a multi-disciplinary open access archive for the deposit and dissemination of scientific research documents, whether they are published or not. The documents may come from teaching and research institutions in France or abroad, or from public or private research centers.
L'archive ouverte pluridisciplinaire HAL, est destinée au dépôt et à la diffusion de documents scientifiques de niveau recherche, publiés ou non, émanant des établissements d'enseignement et de recherche français ou étrangers, des laboratoires publics ou privés. 


\title{
A New Testing Method to Investigate the Compacting Behaviour of Fresh Concretes Under Impact Loading
}

\author{
S. Pattofatto $\cdot$ A. Poitou $\cdot$ H. Tsitsiris $\cdot$ H. Zhao
}

S. Pattofatto $\cdot$ H. Tsitsiris $\cdot$ H. Zhao

LMT Cachan, E.N.S. de Cachan, C.N.R.S.-U.M.R. 8535,

61 avenue du Président Wilson, 94235 Cachan Cedex, France

e-mail: pattofat@1mt.ens-cachan.fr

\section{A. Poitou}

Institut GeM, Ecole centrale de Nantes,

CNRS, Université de Nantes,

1 rue de la Noe BP 92101, 44321 Nantes Cedex, France

\begin{abstract}
This paper presents a new instrumented Proctor test using a Hopkinson bar which allows for the original measurement of forces and velocities during the impact loading on soft fresh concrete samples. For this purpose, the specific points of using low impedance Nylon bar as well as the two-point measurement method to recover coupled waves are discussed. The whole test consists of successive impacts of low velocity (less than $3 \mathrm{~m} / \mathrm{s}$ ) exerted on the compressible specimen of a fresh concrete. The proposed original measurement allows for a quantitative comparison of the behaviour of the fresh concrete submitted to quasi-static and impact compaction. It shows that impact compaction is more efficient than quasi-static case. However, the increase of the impact velocity seems to reduce the efficiency. There exists probably an optimal loading path. The further understanding of the behaviour of fresh concrete under low velocity impact should be an interesting way to improve the industrial compacting process.
\end{abstract}

Keywords Fresh concrete - Compaction - Proctor test . Hopkinson bars

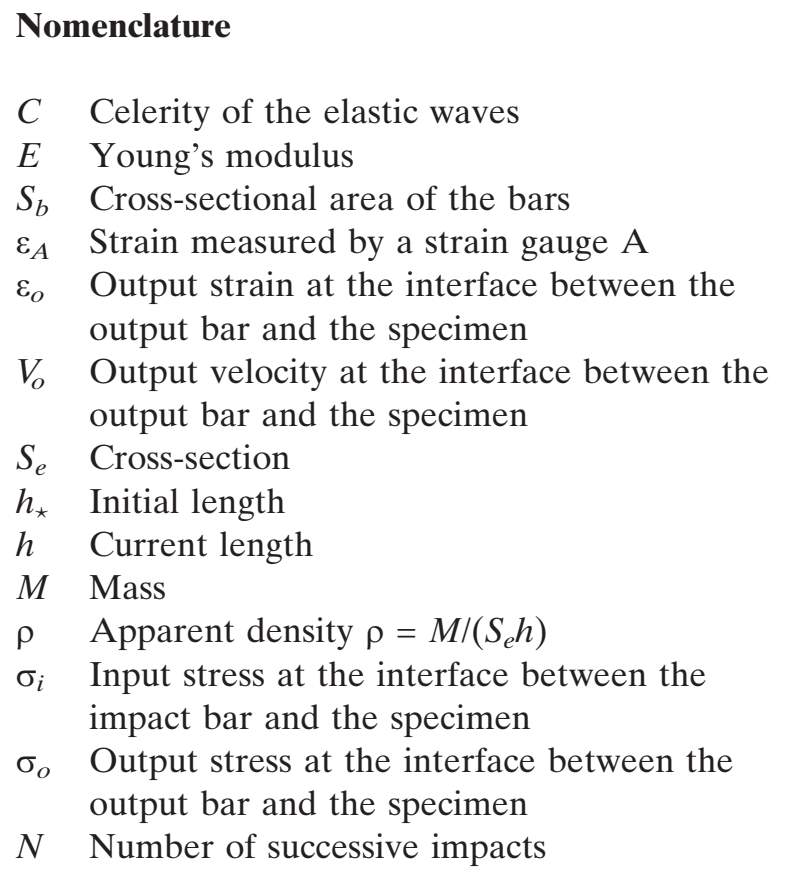

\section{Introduction}

The prefabricated concrete products are widely used in the world and have an important economic interest. They are generally made from semi-liquid soft fresh concrete by moulding. During the moulding process, it is necessary to compact the fresh concrete in the mould to increase its density (up to $60 \%$ from that of initial soft fresh concrete) to obtain a good strength of final products. This compaction is generally performed by a combined action of compression and vibration. In practice, it is well known that the efficiency in 
compacting fresh concretes strongly depends on the added vibration.

However, the current understanding of the compacting efficiency of the vibration is still rather poor, mainly because of the lack of reliable experimental results. Indeed, there are only few research works on the influence of the vibration on the settling of concrete $[3,9,17]$. Those previous works are generally based on experiments for which the fresh concrete specimen is compacted in a mould lying on a vibrating support. Therefore, the compacting efficiency related to different type of vibrations is qualitatively investigated. However, no evident general conclusion can be made because of the inaccurate knowledge of the real boundary and loading conditions, and the important scatter on the fresh concrete samples.

It is also noted that the vibrating system in the industrial manufacturing process in Europe generates in fact successive strikes on the mould containing the products. The frequency is about $50 \mathrm{~Hz}$ in the case of very dry concrete [3]. In order to investigate this complex process, one way is to consider the forming process as a series of independent impulsive low velocity impacts (which is anyway more realistic than a smooth sinusoidal vibration assumption). For this purpose, an experimental device that allows to reproduce the successive impacts on fresh concrete is necessary. Such a device can be used as a tool for the analysis of the compacting behaviour of the material. It could provide a better understanding the efficiency of impact loading compaction and hopefully lead to the optimization of the existing industrial manufacturing process.

\section{The Proctor Test}

As the only normalised test applied to the study of impact compaction is the Proctor test [1], we are focused on this technique. The standard Proctor test is a common test to characterize of the compactibility of soils [14]. It is commonly used to highlight the influence of the water content on the behaviour of soils during compaction $[6,16]$. The soil sample is compacted in a cylindrical mould under the action of repeated impacts of a falling weight (Fig. 1). The measurements are limited to (i) the height of the sample, giving the apparent densification, and (ii) the total energy applied, depending on the falling height and the number of impacts. As a result, it allows to plot curves depicting the evolution of the apparent density versus the accumulated energy provided for the compaction.
Fig. 1. The standard Proctor test

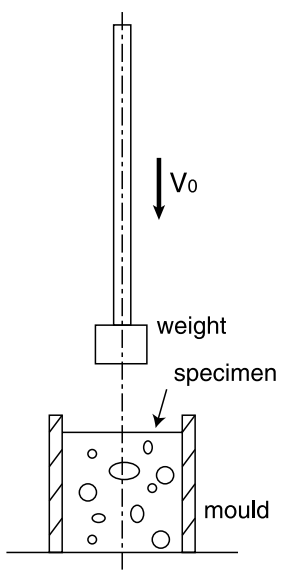

However, one important parameter of the compacting process is the maximum force applied (for the compacting machine design for instance). Indeed, the force history recording will contribute also for a better understanding of the compacting process. It should be possible to instrument the drop hammer by an accelerometer like an instrumented drop weight test, but such a measuring method is known to be not accurate enough. In this paper, we propose an instrumentation of the standard Proctor test using a reliable and accurate measuring technique under impact conditions: the Hopkinson bars.

\section{The Hopkinson Bar Measurement Technique}

The Hopkinson bar is a well-known measuring technique of impact impulse [7] that has been used for material testing at high strain rate since the 50's [8]. The measuring system is made of a long thin rod instrumented with strain gauges.

In the most popular configuration, the Split Hopkinson Pressure Bar (SHPB) test [4, 8], two long thin rods serve as loading frame as well as measuring system. The studied material is a cylindrical disc sample of small height $h_{\star}$, which is crushed between the two bars as depicted in Fig. 2. Strain gauges are cemented on both bars, which provide the basic measurements of wave impulses propagating in the bars. Indeed, the impact of the striker at the free end of the input bar creates a compressive longitudinal incident wave, $\varepsilon^{i}$. Once it arrives at the bar-specimen interface, (i) a reflected wave, $\varepsilon^{r}$, is developed in the input bar, and (ii) a transmitted wave, $\varepsilon^{t}$, is induced in the output bar. From these basic experimental data (incident, reflected and transmitted waves), forces $F$ and velocities $V$ at both faces of the specimen can be deduced [see equation (1), the waves are supposed 
Fig. 2. The standard split Hopkinson pressure bar test

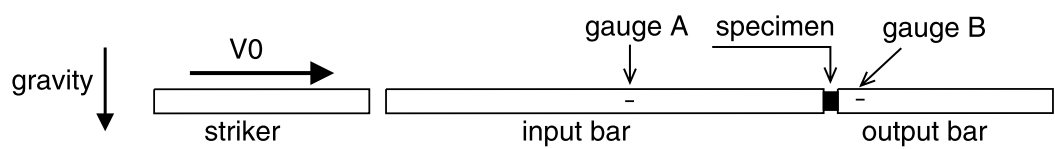

to propagate elastically, with no attenuation nor dispersion].

$$
\begin{array}{lll}
F_{i}=E S_{b}\left(\varepsilon^{i}+\varepsilon^{r}\right) & \text { and } & V_{i}=C\left(\varepsilon^{i}-\varepsilon^{r}\right) \\
F_{o}=E S_{b} \varepsilon^{t} & \text { and } & V_{o}=C \varepsilon^{t}
\end{array}
$$

where $E$ denotes Young's modulus, $S_{b}$ the crosssectional area and $C$ wave speed, of the bars. The subscript $i$ or $o$ denote that the value is taken at the interface between the specimen and respectively the input and the output bar. The material behaviour can be achieved if strain and stress fields within the sample are homogeneous. The average stress-strain relation $(\bar{\sigma}, \bar{\varepsilon})$ of the crushed material can be calculated with equation (2).

$\bar{\sigma}(t)=\frac{F_{\mathrm{i}}}{S_{e}}=\frac{F_{\mathrm{o}}}{S_{\mathrm{e}}}$

$\bar{\varepsilon}(t)=\int_{0}^{t} \frac{V_{\mathrm{o}}-V_{\mathrm{i}}}{\mathrm{h}_{\star}} d t$

where $S_{e}$ is the cross-sectional area of the specimen.

Another classical configuration is the Direct Impact Hopkinson Pressure Bar (DIHPB) test [5]. In that case, the specimen is placed on the output bar so that it is crushed directly, without the use on the input bar (see Fig. 3). It allows to achieve higher strain rates, but the measurement is limited to the output side only. The homogeneity of stress and strain into the specimen has therefore to be accepted.

In both configurations, the measuring technique using Hopkinson bars relies on the proportionality between stress, strain and particle velocity associated with the two "single waves" propagating in opposite directions. Once they are known, they are time shifted to the desired cross-section (bar specimen interfaces in fact) and the most simple case is the one of a perfect propagation of the wave in the direction $x$, on a distance $d$, given by equation (3).

$\sigma(x+d, t)=\sigma\left(x, t-\frac{d}{C}\right)$

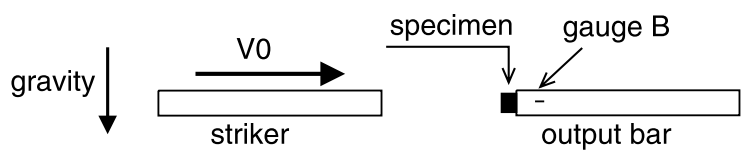

Fig. 3. The direct impact Hopkinson pressure bar test
Particular Use of Hopkinson Bar Technique to Instrument Proctor Test

The device presented in next section of this paper is an instrumented Proctor test, based on Hopkinson bars. Regarding the Hopkinson bar measurement technique, it can be viewed as a combination of both configurations: the SHPB because the measurement is available on both sides of the specimen, and the DIHPB because the striker crushes directly the specimen. Moreover, it can be seen that there are two specific points in order to use this Hopkinson bar technique in an instrumented Proctor test.

Firstly, the measuring accuracy depends on the strength of tested sample. Soft Nylon bars [18] are therefore used, necessary for the measurement of very weak forces in the case of non-solid material studies (see also $[11,15])$.

Secondly, the directly measurable quantities such as strains or velocities everywhere in a bar are the sum and the difference of the two elementary waves. The classical technique uses long bars and a short loading pulse so that there exists a cross-section where the total incident pulse and the first part of reflected wave (of the same duration) can be recorded separately. There exists then a maximum observation duration depending on the length of the bar, and the measuring duration of a classical instrumented bar is limited [4] to $L / C, C$ being wave speed and $L$ the length of the bar. As we can see in this paper, the instrumented Proctor test using a falling bar has a long impact duration. Then, a wave separation scheme based on two-point measurements is also necessary to be applied.

\section{Experimental Procedure}

New Instrumented Proctor Test

Using Hopkinson Bars

The proposed new instrumented Proctor test consists in compacting the specimen of fresh concrete under repeated impacts of a long instrumented Hopkinson pressure bar. The whole experimental setup, shown on Fig. 4, is fixed on a vertical rigid support. The Hopkinson bar falls down to strike the fresh concrete specimen in the same way as in the Proctor test. The 


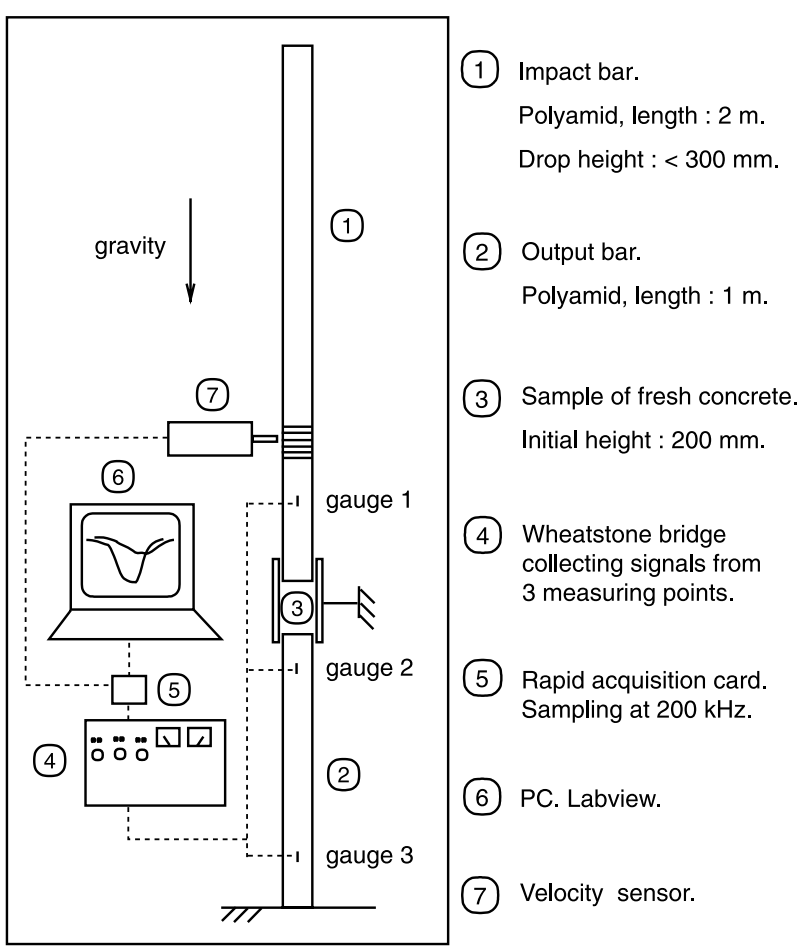

Fig. 4. Experimental apparatus

studied specimen of fresh concrete is put into the 10 $\mathrm{mm}$ thick steel mould, which has a diameter of $62 \mathrm{~mm}$ and is made up of two parts so that the specimen can be kept after a complete test. The lateral expansion is quite small and supposed to be negligible. Such experimental setup allows (i) for the good filling of the mould, (ii) to minimize the initial compaction of the specimen, (iii) to apply repeated impacts on the same specimen, (iv) to apply low velocity impacts, less than $3 \mathrm{~m} / \mathrm{s}$.

A complete test is composed of a series of repeated impacts imposed at constant impact velocity by means of a constant drop height limited to $300 \mathrm{~mm}$. For each impact, the test procedure is the following: (i) the input bar is lifted and dropped manually, (ii) the strain measurements are automatically triggered using the input bar gauge signal, (iii) the final height of the specimen after each impact is measured manually. The complete test, including about thirty impacts, lasts about 10 minutes.

The dimension of the instrumented Proctor test is the following: the impact input bar is $2 \mathrm{~m}$ long, and the specimen rests on an $1 \mathrm{~m}$ long output bar which allows besides for the measurement of the wave propagation velocity into the concrete. Bars are made of polyamide PA6.6 in order to measure weak forces $[4,20]$. The bars have a Young's modulus of $3.1 \mathrm{GPa}$ and the celerity of the wave is equal to $1730 \mathrm{~m} / \mathrm{s}$. The diameter of the bars is $61 \mathrm{~mm}$ so that the specimen is held confined between the bars and the mould. The output bar rests directly on the ground so that it serves also as a reference for the measurement of the height of the specimen after each impact.

The advantage of this new testing setup using Hopkinson bar lies in the measurement of forcesdisplacement time history, given by strain gauges (equation 1). On each measurement point, two gauges are cemented, diametrically opposed and linked to a half-Wheatstone bridge. In this way, the bending of the bar is not taken into account. The analogical signal is converted into a numerical signal using a rapid acquisition card, the sampling frequency of which is $200 \mathrm{kHz}$.

\section{Data Processing and Validation of Measurement}

In this particular configuration of Hopkinson bars, the main difficult lies in the fact that the raw signals of strain gauges can not be directly used as in a classical SHPB setup. This is because the duration of a falling impact is long (about $6 \mathrm{~ms}$ ) and the length of the bars is not sufficient to record separately the two waves propagating on the opposite directions (a bar of $20 \mathrm{~m}$ should be necessary). Indeed, when the signal measured by a strain gauge contains the sum of superposed compression waves, it is no longer possible to apply the timeshifting formula (equation 3) and the proportionality between stress, strain and particle velocity (equation 1) is no more valid. To overcome this difficulty, a twopoint measurement method should be applied to each bar. Two measuring points are effectively used for the output bar whereas the free end of the impacting bar serves as the second measuring point for the input bar.

This two-point measurement method introduced by Zhao and Gary [19] is based on the separation of every

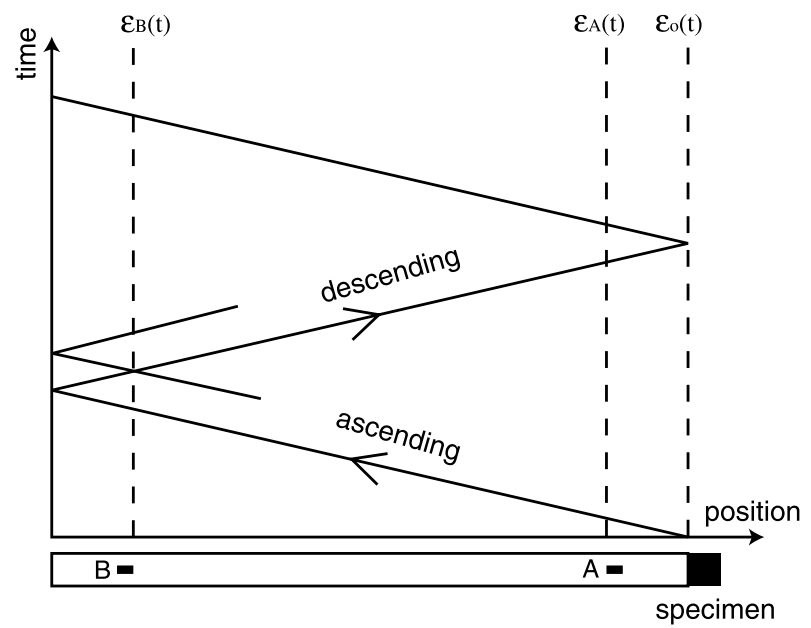

Fig. 5. Illustration of the basis for the separation of waves 
Fig. 6. Raw measurements at the three measurement points. Impact number 3

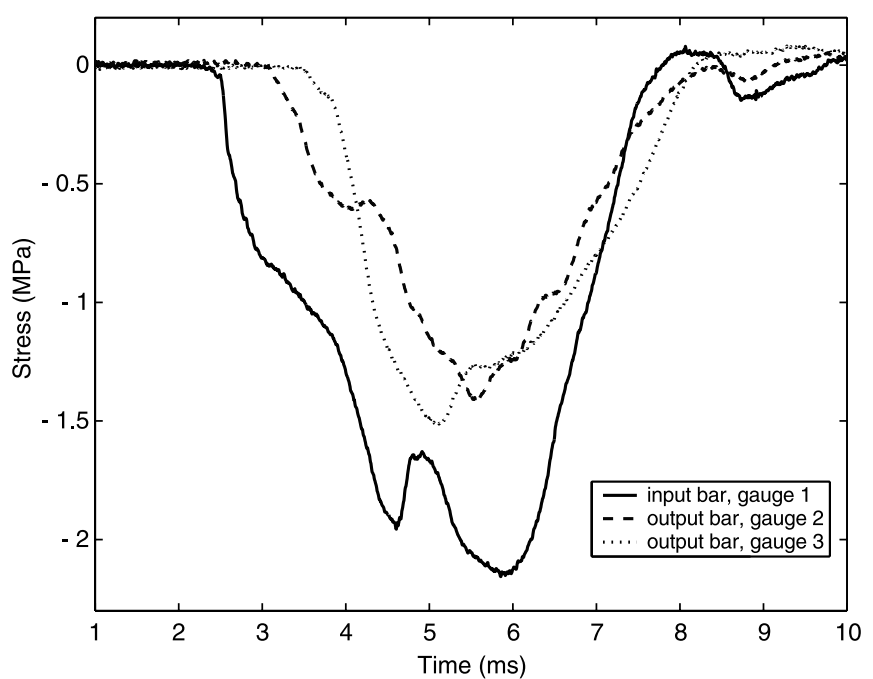

complex superposition of waves into two elementary waves, propagating in opposite directions. Here we denote these two waves ascending $\varepsilon^{a s c}(t)$ and descending $\varepsilon^{\text {desc }}(t)$ as depicted on the example of Fig. 5 that can be viewed as a representation of the output bar in our experiments.

In this case, the superposition principle of the waves at the measurement points gives:

$\varepsilon_{A}(t)=\varepsilon_{A}^{a s c}(t)+\varepsilon_{A}^{\text {desc }}(t)$
$\varepsilon_{B}(t)=\varepsilon_{B}^{\text {asc }}(t)+\varepsilon_{B}^{\text {desc }}(t)$

Using the time-shifting formula (3), the strain and velocity can be calculated at the interface between the bar and the specimen as follows:

$$
\begin{aligned}
& \varepsilon_{o}(t)=\varepsilon_{A}^{a s c}\left(t-t_{A}\right)+\varepsilon_{A}^{\text {desc }}\left(t+t_{A}\right) \\
& V_{o}(t)=C\left(\varepsilon_{A}^{a s c}\left(t-t_{A}\right)-\varepsilon_{A}^{\text {desc }}\left(t+t_{A}\right)\right)
\end{aligned}
$$

where $A$ is the location point of the gauge and $t_{A}$ is the time for the wave to travel from $A$ to the interface. Considering only the equation of the strain, it can be expressed in terms of a function $g$ depending on the measurements given by the two gauges, and $\frac{\Delta t}{2}$ which is the time for the wave to travel between the gauges:

$\varepsilon_{o}(t)=\varepsilon_{o}\left(t-\frac{\Delta t}{2}\right)+g\left(\varepsilon_{A}, \varepsilon_{B}\right)$

The signal is therefore iteratively calculated from the measurements $\varepsilon_{A}(t)$ and $\varepsilon_{B}(t)$, and the initial stress and velocity of the bars (detailed method in $[10,19]$ ).
The stress is therefore calculated using the elastic behaviour of the bar:

$\sigma_{o}=E \frac{S_{b}}{S_{e}} \varepsilon_{o}$

It is emphasised that the derived formula (5) and (6) are based on the assumption of perfect one-dimensional wave propagation theory even if the bars are viscoelastic and have a large diameter. Such a simplification neglecting wave dispersion effect is still valid because the impact velocity is low and high frequency components in the spectrum of the signal are rather limited. Indeed, the ratio $a / \Lambda[2,13]$, diameter of the bar, $a$, and wavelength of the wave, $\Lambda$ ] to quantify the effect of dispersion, is about 0.01 , which is very low. The same conclusion can be done about attenuation, which is negligible in our case [19].

A computer program of waves separation has been implemented and validated using a bar against bar test [12]. The results finally show that the calculation of the stress is not very sensitive to the separation of waves. In fact, this is due mainly to the fact that gauges 1 and 2 (see Fig. 4) are cemented close to the interface (12 $\mathrm{mm})$. On the contrary, regarding the calculation of the displacement, the separation of the waves is

Table 1 Formulation of the fresh concrete, given in weight $\%$ of the dry material

\begin{tabular}{llll}
\hline Coarse grains & Sand & Cement & Water \\
\hline $35 \%$ & $57.3 \%$ & $7.7 \%$ & $7.3 \%$ \\
\hline
\end{tabular}


Fig. 7. Variation of density versus number of impacts

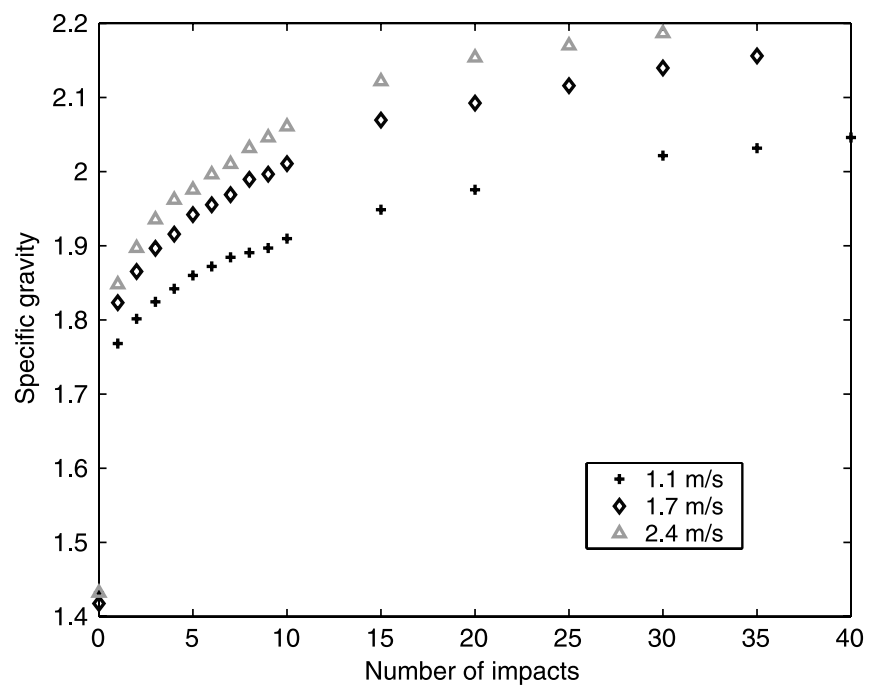

necessary because the calculation of the velocity is based on the difference of the two elementary waves [see equation (5)].

Another remark is that the standard Split Hopkinson Pressure Bar (SHPB) formulas can not be directly used because the assumption of the homogeneity of stress and strain in the specimen is not satisfied. Indeed, our testing results, as shown in Fig. 6, show that the homogeneity of stresses into the specimen is never achieved. The post-mortem observation of the specimen shows also that the density of the compacted fresh concrete is not homogeneous in the height [12]. As a consequence, the analysis will be based only on the independent measurements obtained at both sides of the specimen, and especially at the input bar/specimen interface.

\section{Results}

Material and Specimen Preparation

Tests results presented below are those performed on a particular fresh concrete for industrial use, the formulation of which is given in Table 1 .

The granular phase (aggregates and sand) is polydisperse: grain sizes range from 0 to $6 \mathrm{~mm}$. Coarse grains are $4 / 6 \mathrm{~mm}$ slag granulates. Sand is made of crushed grains and covers all the low granulometry ( $0 /$ $4 \mathrm{~mm}$ slag granulates). This fresh concrete has therefore, empirically speaking, a good propensity to compaction. Before preparing the material, all the granulates are dried at the ambient atmosphere in order to control the weight of water introduced into
Fig. 8. Variation of density versus number of impacts

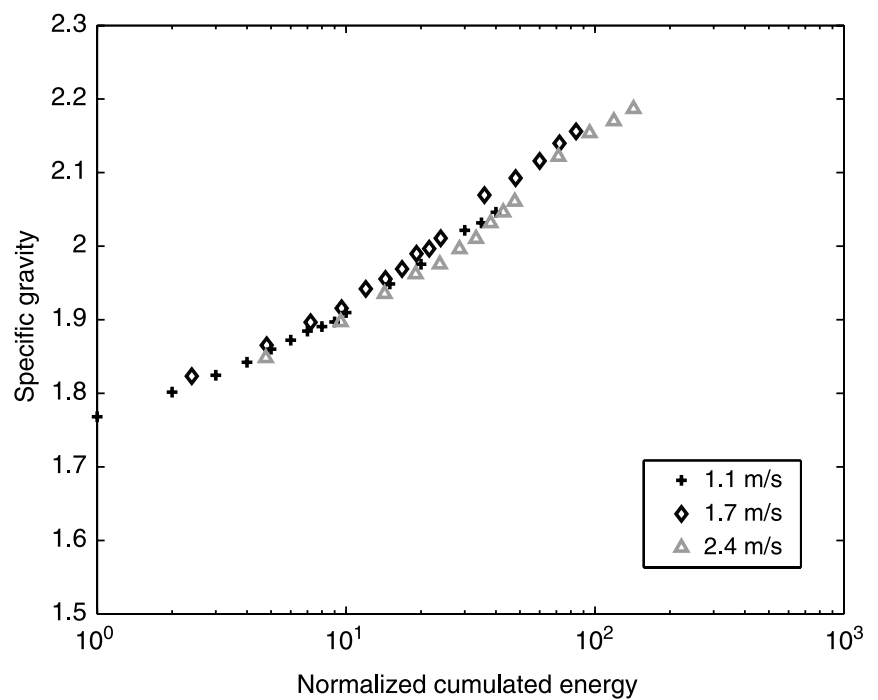


Fig. 9. Measurement of stresses at the interfaces. Impact number 1

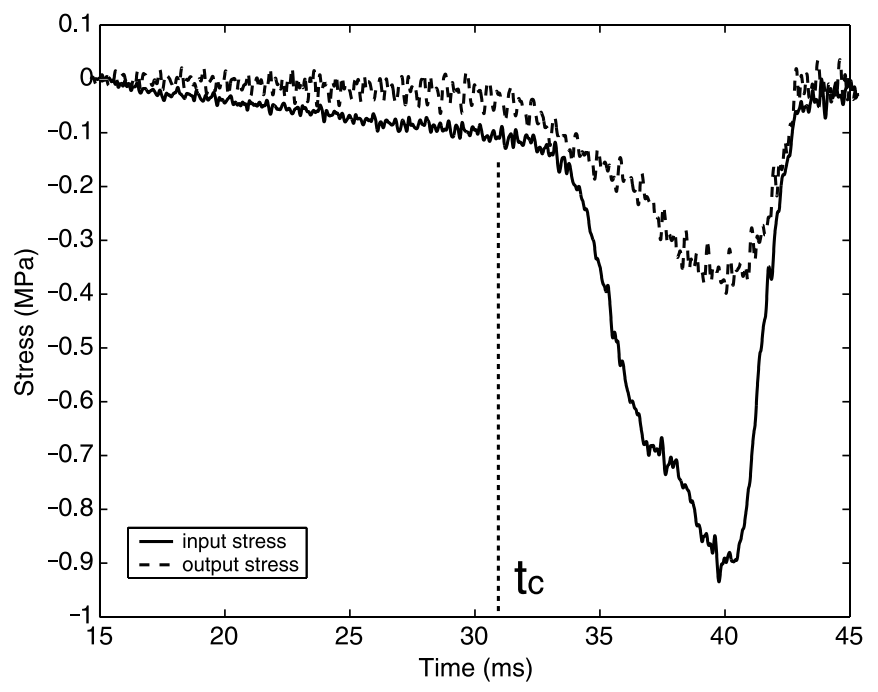

the mixture. All the compositions are mixed during 2 min in a planetary mixing device, which is cleaned and dried before each use. The material is introduced into the mould in a "rain" way. In general, the test begins 5 min after mixing and the whole test lasts about $15 \mathrm{~min}$. It is supposed that there is no rheology change during the test.

For different sets of tests, a constant volume of material is introduced into the mould with a good repeatability of the corresponding mass $(980 \mathrm{~g} \pm 5 \%$ ). The specimen of fresh concrete is cylindrical, of diameter $\phi 62 \mathrm{~mm}$, and initial height $200 \mathrm{~mm}$. The initial density of the specimen is about $1400 \mathrm{~kg} / \mathrm{m}^{3}$. The diameter of the specimen is ten times larger than the maximum size of the grains. In consequence, we assume then that there is no scale effect.

\section{Standard Measurements as a Proctor Test}

Direct results are given by the standard Proctor test measurements. The results show the variation of the apparent density $\rho$ versus the number of impacts $N$. The observation of the specimen after the test allows to confirm qualitatively that the material is not homogeneous in the height [12]. That is the reason why the apparent density $\rho$ is considered.

The results of three different complete tests are presented in Fig. 7. They show the variation of the density $\rho$ versus the number of impacts $N$, that tends toward a stable value. We can notice that $55 \%$ of the total densification is achieved within the very first impact. After the tenth impact, the densification process tends to be very slow. The influence of an
Fig. 10. Measurement of stresses at the interfaces. Impact number 2

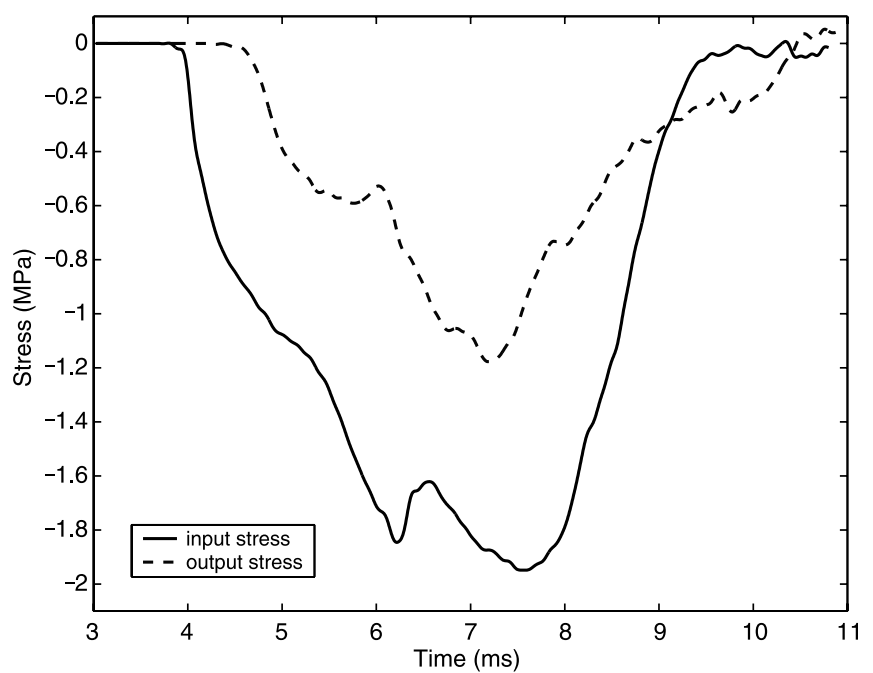


Fig. 11. Curve of compactibility associated to a complete test

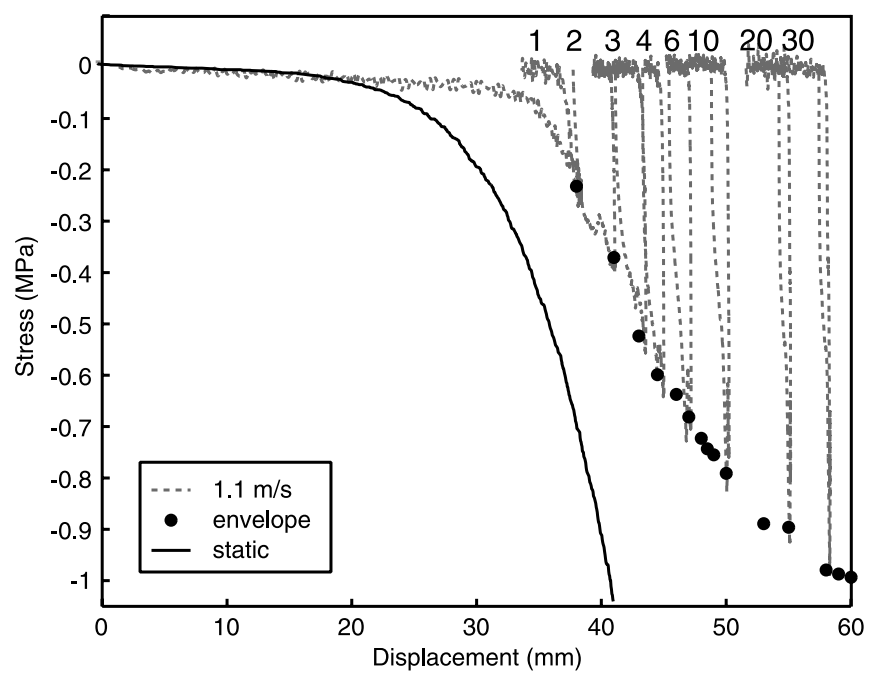

increasing drop height of the impact bar is an increase of the density achieved for a given number of impacts.

The standard Proctor semi-logarithmic curve is given in Fig. 8. The energy is normalized by the energy of one impact at the smallest velocity. It shows that the three different tests are equivalent on the Proctor curves. Clearly, such results provide only very limited information on the studied materials.

\section{Contribution of the Hopkinson Bar Measurement}

The measurements given by the Hopkinson bars are presented here by plotting the stress versus the time $\sigma_{i}(t)$, or versus the apparent density $\sigma_{i}(\rho)$. Since the stress field within the specimen is not homogeneous, the stress is taken as the impact stress, measured at the interface with the impact bar. It is interesting to note that the initial impact on the fresh concrete (Fig. 9) is very different from successive impacts afterwards (Fig. $10)$.

In fact, during the first impact (Fig. 9), the measured stress remains very low until the instant $t_{c}$. After $t_{c}$, the signal is similar to those of next impacts (see Fig. 10), except that the rapid increase of the stress occurs first in the output bar. For next impacts it happens first in the input bar. The particularity of the initial impact reveals probably very different deforming regime. Here in this paper, we focus only on general aspect of successive impact tests after the first initial impact.

The measurement of impact force and displacement history by the Hopkinson bars provides a possibility to compare quantitatively quasi-static and impact regimes. Figure 11 shows a result of such a comparison. In the quasi-static case, the compression is applied with a constant velocity of $0.1 \mathrm{~mm} / \mathrm{s}$ on a standard hydraulic
Fig. 12. Comparison of the compactibility of the fresh concrete submitted to dynamic (dots, with the number of impacts) and quasi-static (solid line) load

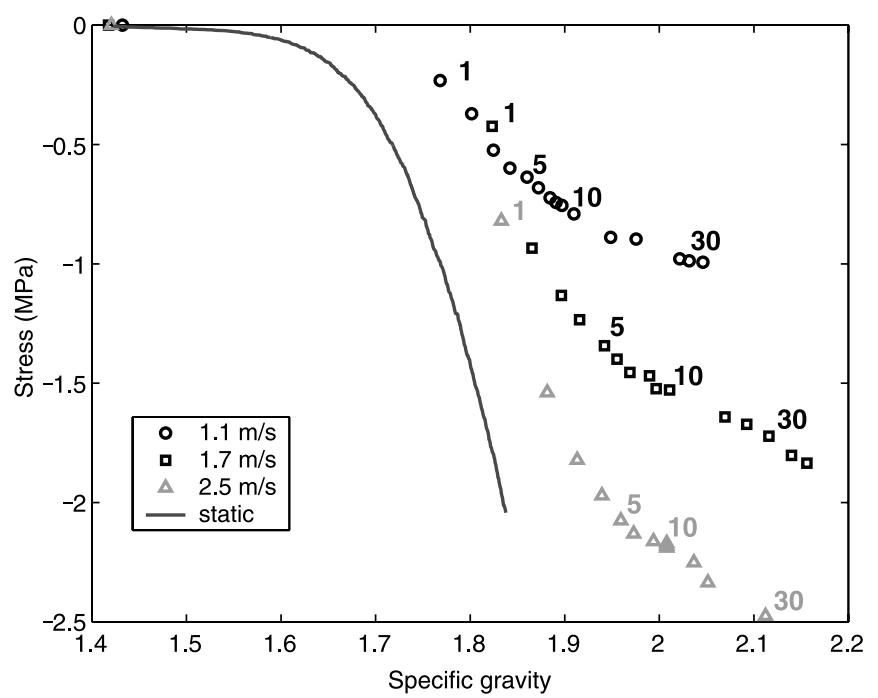


testing machine with the same mould as for the impact tests. For the impact case, if we concatenate all the successive stress-displacement curves for all the impact tests, we can construct a general stress-displacement curve for the whole test. The dashed lines correspond to elementary impact tests, the displacement being calculated by the program using equation (5). All the elementary curves are then offset so that the maximal value of the displacement be consistent with the value of the height of the specimen measured after each impact. The dots correspond to the maximal values of stress during each impact. The results show that the impact loading is more efficient for the fresh concrete compaction, in the sense that the energy necessary to compact the concrete to a given level of displacement is smaller under impact loading (up to 30 impacts).

One can also use another curve depicting the variation of stress versus density for a complete test. In order to show the influence of impacting velocities, results of three complete tests with different impact velocities are compared in Fig. 12. Here only the envelope of all the curves $\sigma_{i}(\rho)$ calculated from each impact is plotted for the reason of readability. They are compared to a standard nominal stress versus apparent density curve, calculated from a compaction test performed in quasi-static conditions. The results show that the fresh concrete submitted to repeated impacts can be compacted to higher densities with lower stresses. When the drop height of the input bars increases, the densification is getting higher and more rapid. However, the compacting efficiency is reduced because the increase of the impact velocity induces an increase of impacting stresses.

\section{Conclusions}

An original test has been presented to measure the compacting efficiency of soft compressible fresh concretes under impact loading. It has been used to study the compacting behaviour of one particular moulded fresh concrete. The test proposes an instrumentation of a standard Proctor test by using Hopkinson bars, which allow for the measurement of stress and displacement in transitory dynamics. Nylon bars are necessary to be used given that the fresh concrete is highly compressible under low stresses. The presented instrumentation allows for the following original results:

- the compaction regime for the initial impact is very different from next successive impacts,
- the compaction under impact loading $(1.1 \mathrm{~m} / \mathrm{s}$ to $2.5 \mathrm{~m} / \mathrm{s}$ ) is more efficient than the quasi-static case in the sense of less energy consuming (lower stresses),

- however, the increase of impacting velocity leads to higher stresses at a given compaction level.

Such result show that impact loading is more efficient than quasi-static one and it seems that lower velocity impact induces a lower stress level. An optimised industrial compacting process is then possible.

\section{References}

1. ASTM (2000) Standard methods for laboratory compaction characteristics of soil using standard effort $[12,400 \mathrm{ft}-\mathrm{lbf} /$ $\left.\mathrm{ft}^{3}\left(600 \mathrm{kN} / \mathrm{m}^{3}\right)\right]$, ASTM Standard in Building Codes, West Conshocken, PA.

2. Chree C (1889) The equations of an isotropic elastic solid in polar and cylindrical coords, their solutions and applications. Cambridge Philos Soc Trans 14:250-369.

3. Cusens AR (1958) The influence of amplitude and frequency in the compaction of concrete by table vibration. Mag Concr Res 10:79-86.

4. Davies EDH, Hunter SC (1963) The dynamic compression testing of solids by the method of the split Hopkinson pressure bar. J Mech Phys Solids 11:155-179.

5. Hauser FE (1966) Technique for measuring stress-strain relations at high strain rate. Exp Mech 6:395-402.

6. Holtz RD, Kovacs WD (1981) An introduction to Geotechnical Engineering, Prentice-Hall Edition.

7. Hopkinson B (1914) A method of measuring the pressure produced in the detonation of high explosives or by the impact of bullets. Philos Trans-R Soc Lond 213:437-456.

8. Kolsky H (1949) An investigation of the mechanical properties of materials at very high rates of loading. Proc Phys Soc 62:676-700.

9. Legrand C, Gourves R (1975) Etude de l'influence de l'accélération de vibration sur les propriétés rhéologiques des mélanges de sable ou de ciment et d'eau. Essai de definition d'une zone de vibration optimale. CRAS Paris $t$. 280.

10. Lundberg B, Henchoz A (1977) Analysis of elastic waves from two-point strain measurement. Exp Mech 17:213-2178.

11. Ogawa K (2003) Dynamic behavior of viscous fluid at high rate of shear using through bar method. J Phys, IV France 110:435- 440.

12. Pattofatto S, Zhao H, Poitou A (2003) Experimental analysis of fresh concrete under dynamic loading. J Phys IV France 110:447-451.

13. Pochhammer L (1876) Uber die fortpflanzungsgeschwindigkeiten kleiner schwingungen in einem unbergrenzten isotropen kreiszylinder. J Reine Angew Math 81:324-336.

14. Proctor RR (1933) First of four articles on the design and construction of rolled-earth dams. Fundamental principles of soil compaction. Eng News-Rec 111:245-248.

15. Semblat JF, Luong MP, Gary G (1999) 3d-Hopkinson bar: new experiments for dynamic testing on soils. Arch Mech 43(4):499-517.

16. Struble L, Kim TY, Zhang H (2001) Setting of cement and concrete. Cem Concr Aggreg, CCAGDP 23:88-93. 
17. Tattersall GH, Baker PH (1988) The effect of vibration on rheological properties of fresh concrete. Mag Concr Res 40:79-89.

18. Zhao H, Gary G (1995) A three dimensional analytical solution of the longitudinal wave propagation in an infinite linear viscoelastic cylindrical bar. Application to experimental techniques. J Mech Phys Solids 43:1335-1348.
19. Zhao H, Gary G (1997) A new method for the separation of waves. Application to the SHPB technique for an unlimited duration of measurement. J Mech Phys Solids 45(7):11851202.

20. Zhao H, Gary G, Klepaczko JR (1997) On the use of a viscoelastic split hopkinson pressure bar. Int J Impact Eng 19(4):319-330. 